\title{
Aplicação e avaliação de uma metodologia de aprendizagem ativa (tipo ISLE) em aulas de Mecânica, em cursos de Engenharia
}

\author{
Application and evaluation of an active learning methodology (ISLE type) in mechanics classes, in \\ engineering courses \\ J. E. Parreira*1 \\ ${ }^{1}$ Pontifícia Universidade Católica de Minas Gerais, Departamento de Física e Química, Belo Horizonte, MG, Brazil
}

Recebido em 5 de Junho, 2017; Revisado em 11 de Junho, 2017; Aceito em 14 de Junho, 2017.

\begin{abstract}
Neste trabalho será apresentada uma metodologia utilizada no curso de Mecânica, disciplina do primeiro ou segundo semestre de cursos de Engenharia da PUC-Minas, com a utilização de roteiros com caráter construtivista. Nessa proposta, os estudantes desenvolvem conceitos e ferramentas da Mecânica através da execução de experimentos e de discussões com os outros alunos e com a professora. Não há aulas expositivas durante o semestre. Essa metodologia foi inspirada no trabalho do grupo liderado por Engenia Etkina, na Universidade de Rutgers, nos Estados Unidos. A proposta é que os estudantes aprendam Física de forma semelhante à que os cientistas constroem o conhecimento. A avaliação da metodologia foi feita através de pré e pós-testes, FCI (Force Concept Inventory), e questionários para avaliação das opiniões dos estudantes. Os resultados dos questionários de satisfação foram positivos em todas as turmas. Já os resultados quantitativos do FCI indicam que a metodologia foi satisfatória nas turmas de $2^{\circ}$ período e não satisfatória nas turmas de $1^{\circ}$ período.
\end{abstract}

Palavras-chave: aprendizagem ativa, Ensino de Física, ISLE.

\begin{abstract}
This paper will present a methodology used in the course of Mechanics, discipline of the first or second semester of Engineering courses of PUC-Minas, using constructivist scripts. In this proposal, students develop Mechanics concepts and tools through the execution of experiments and discussions with the other students and with the teacher. There are no lectures during the semester. This methodology was inspired by the work of the group led by Engenia Etkina, at Rutgers University in the United States. The proposal is that students learn Physics in similar way which scientists build knowledge. The evaluation of the methodology was done through pre and post-tests, FCI (Force Concept Inventory), and questionnaires to evaluate students' opinions. The results of the satisfaction questionnaires were positive in all the groups. The quantitative results of the FCI indicate that the methodology was satisfactory in the classes of the 2 nd period and not satisfactory in the classes of the 1st period.
\end{abstract}

Keywords: active learning, Physics Education, ISLE.

\section{Introdução}

O interacionismo é um paradigma do desenvolvimento psicológico do ser humano, com importantes implicações pedagógicas, que floresceu no século passado, tendo Piaget, com o interacionismo construtivista, e Vigostki, com o sócio-interacionismo, como seus representantes mais significativos [1]. Essas teorias interacionistas do desenvolvimento estão fortemente presentes entre os atuais estudos nas áreas de educação e ensino, especialmente no Brasil. Uma implicação pedagógica do paradigma interacionista é a consideração de que a aprendizagem ocorre de forma muito mais eficaz a partir da vivência ou participação ativa e experiencial de quem aprende, em contraponto a uma metodologia tradicional que o coloca como um aprendiz passivo, como normalmente

*Endereço de correspondência: prof.julia.parreira@gmail.com se encontram os alunos em aulas expositivas. A criação de situações nas quais os estudantes aprendam a partir de suas experiências, de suas reflexões, da interação e do diálogo com os colegas e o professor tem se mostrado mais eficiente para a aprendizagem do que a interação instrutiva das aulas expositivas [2]. Essas ideias são, muitas vezes, identificadas com um paradigma construtivista. Nas palavras dos próprios Piaget e Vigotski:

"(...) cada vez que ensinamos prematuramente a uma criança alguma coisa que poderia ter descoberto por si mesma, esta criança foi impedida de inventar e conseqüentemente de entender completamente. Isto obviamente não significa que o professor deve deixar de inventar situações experimentais para facilitar a invenção de seu aluno." [3]

"A experiência prática mostra também que o ensino direto de conceitos é impossível e infrutífero. Um professor que tenta fazer isso geralmente não obtém qualquer 
resultado, exceto o verbalismo vazio, uma repetição de palavras pela criança, semelhante à de um papagaio, que simula um conhecimento dos conceitos correspondentes, mas que na realidade oculta um vácuo." [4]

Embora o construtivismo seja um dos mais influentes paradigmas educacionais entre os estudiosos da educação no Brasil, nossas salas de aula sediam mais situações de interações instrutivas do que construtivistas. Se considerarmos as salas de aula de Física do Ensino Superior, esse desbalanço é ainda maior, prevalecendo as aulas expositivas.

Mas uma mudança tem ocorrido nos últimos anos e diversas práticas e metodologias construtivistas estão sendo desenvolvidas e adotadas por professores de Física do Ensino Superior, especialmente nos últimos 30 anos, com maior intensidade nos Estados Unidos. Uma expressão dessa mudança pode ser verificada observando-se o perfil dos trabalhos vencedores da Medalha Millikan, prêmio anual fornecido pela "American Association of Physics Teacher" em reconhecimento a grandes contribuições para o ensino de Física. Entre os acadêmicos que conquistaram o prêmio, estão: Lillian McDermott, ganhadora em 1990, elaborou os chamados "Tutoriais" $[5,6]$. Em suas aulas os estudantes trabalham em grupos, resolvendo as questões propostas nesses tutoriais. Erik Mazur, 2008, desenvolveu o "Peer Instruction", no qual os estudantes discutem questões de múltipla escolha durante a aula [7]. Os métodos desenvolvidos por Lillian McDermott e Eric Mazur já são utilizados por diversos professores no Brasil [8-13]. E, ainda, Eugenia Etkina, 2014, elaborou o "Investigative Science Learning Environment" (ISLE), em que os estudantes executam experimentos e desenvolvem os conceitos da Física a partir de suas discussões a respeito das práticas [14]. Essa última metodologia, da qual não foram encontrados registros de sua utilização no Brasil, é também o modelo adotado no trabalho que será relatado neste texto.

Em um estudo realizado em 2016 [2], Korff e colaboradores compararam práticas de ensino-aprendizagem tradicionais, em que as aulas são expositivas, a práticas de aprendizagem ativa, em que o estudante é protagonista efetivo dos procedimentos em sala, mostrando a maior eficiência dos métodos ativos. O estudo realizado abordou a análise de diversos trabalhos que aplicaram o teste FCI ("Force Concept Inventory") para medir o ganho do estudante durante a disciplina e envolveu 50.000 estudantes. O ganho normalizado médio dos estudantes envolvidos em métodos ativos foi de $39 \%$, enquanto o dos estudantes submetidos a métodos tradicionais foi de $22 \%$.

O FCI [15] é um teste composto por 30 questões de múltipla escolha sobre conceitos de Mecânica, criado em 1992, que pode ser utilizado tanto no Ensino Médio quanto no Ensino Superior. Ele é um marco importante para a recente história das metodologias ativas no ensino de Física, tendo em vista que foi justamente a partir de sua criação que houve uma intensificação na pesquisa em ensino de Física e no desenvolvimento e na adoção de práticas e metodologias construtivistas na área. Ele é aplicado como pré-teste e pós-teste. O ganho médio normalizado percentual, $\langle g\rangle=\left\langle\frac{\text { pos-pre }}{100-\text { pre }}\right\rangle$ em que os valores pos e pre estão em percentuais, compara as notas iniciais e finais, resultando em 0 (zero) se as notas permanecem iguais, valores negativos para a piora de desempenho e 100 (cem) para notas finais totais.

O reconhecimento do crescimento de práticas construtivistas e a verificação de sua melhor adequação ao aprendizado têm sido divulgados no meio acadêmico, não só através de seus pesquisadores, mas também por importantes entidades envolvidas com o ensino e a educação, como destacou o editorial da Revista Brasileira de Ensino de Física com o título "Aprendizagem ativa" [16]. Nos últimos anos, várias experiências concernentes ao estudo da Física nos Ensinos Médio e Superior têm sido realizadas no Brasil, abrangendo a aplicação de diferentes metodologias. Eis alguns exemplos: aprendizagem baseada em equipes [17], instrução por pares [8,9]; previsão-observação-explicação [18]; tutorias de Física [10].

Neste texto, será feito um relato sobre a adoção de uma metodologia de aprendizagem ativa, construtivista, em uma disciplina de Física aplicada a turmas de Engenharia no Ensino Superior. Será descrita a experiência e alguns resultados obtidos. Esses resultados constam de testes FCI e questionários de satisfação aplicados às turmas.

\section{O Método ISLE}

A metodologia adotada foi inspirada no trabalho desenvolvido pelo grupo liderado por Eugenia Etkina, na Universidade Rutgers, nos Estados Unidos, cujo registro resultou em material divulgado no site do grupo [19]. A metodologia em questão foi denominada "Investigative Science Learning Environment" (ISLE). A proposta é que os estudantes aprendam Física de forma semelhante àquela utilizada pelos cientistas na construção e aplicação do conhecimento. "Este processo envolve observar, encontrar padrões, construir e testar explicações para os padrões e utilizar múltiplas representações para pensar sobre o fenômeno físico." [20].

As aulas são parecidas com práticas de laboratório de ensino de Física, em que os estudantes recebem materiais e roteiros (os roteiros estão disponibilizados no blog institucional da professora [21]) para executarem experimentos nos quais serão observados determinados fenômenos físicos. Mas há uma diferença essencial entre aulas tradicionais de laboratório de ensino e as aulas do tipo ISLE, na medida em que aquelas geralmente são elaboradas com o intuito de que os estudantes verifiquem as leis da Física, enquanto estas pretendem que os alunos reconstruam as leis da Física através de práticas investigativas, semelhantes ao trabalho de um(a) pesquisador(a) de Física em seu laboratório, traduzindo-se em uma prática essencialmente construtivista.

Além de trabalhar a construção dos conceitos de Física e a habilidade de resolver problemas a partir de situações 
práticas, esta metodologia favorece o uso e a reflexão de habilidades científicas. O processo em questão permite discutir de forma muito natural a questão de como o conhecimento científico é produzido, bem como a validade e as limitações das leis físicas e dos modelos matemáticos, permitindo uma análise crítica do desenvolvimento e dos limites da Ciência.

\section{Contexto de Sala de Aula - Implementação do ISLE}

No trabalho desenvolvido aqui descrito, o ISLE foi implementado com algumas adaptações, como nas questões avaliativas, que não seguiram a proposta do grupo de Rutgers. Alguns dos roteiros foram inspirados nos textos do grupo de Rutgers [19], mas se trata da minoria das práticas.

Com exceção de algumas intervenções da professora ao longo do semestre, verificadas em pequenas frações da aula, não ocorreram aulas expositivas. Os estudantes desenvolviam os conceitos e ferramentas da Física a partir das experiências por eles realizadas, buscando responder às questões propostas no roteiro, através do diálogo com os colegas e com a professora. A função da professora durante a aula foi, a partir da solicitação dos estudantes através de dúvidas ou a partir da observação dos grupos e percepção de impasses, orientá-los, com comentários, fornecendo informações ou levantando outras questões, para que encontrassem eles próprios as respostas e soluções de seus impasses.

A disciplina na qual ocorreu a experiência descrita é a primeira abordagem de Física dos cursos de Engenharia, ministrada no primeiro ou no segundo semestre a partir do ingresso dos estudantes no curso superior, dependendo do curso específico do qual ela faz parte. Esta disciplina integra o currículo de quatro cursos de Engenharia da PUC-Minas. O enfoque é o estudo da Mecânica, sendo adotados, como referência, os livros "Fundamentos de Física, volume 1" [22], "Física 1" [23] e "Física para cientistas e engenheiros, volume 1" [24].

Os resultados aqui apresentados referem-se ao segundo semestre de 2016 (segundo semestre em que a metodologia foi utilizada) e são relativos a duas turmas de $1^{\circ}$ período (uma com 39 estudantes, que será denominada T1a, e outra com 20 estudantes, T1b) e duas de $2^{\circ}$ período (T2a com 12 estudantes, e T2b com 9 estudantes).

Os estudantes trabalharam em grupos de duas a seis pessoas durante as aulas. Eles tiveram autonomia para organizar os grupos, cujas composições poderiam ser alteradas a cada aula. Os alunos tinham previamente acesso online ao roteiro da prática e no início da aula recebiam o material necessário para o experimento a ser realizado (comumente fita métrica, dinamômetros e balanças, dentre outros materiais). Durante o semestre, que constava de dezessete semanas letivas, foram realizadas dezessete práticas. Cada prática durava, em média, uma semana, contemplando duas aulas de cem minutos cada uma.
Nos dias em que se fosse iniciar uma atividade nova, a prática era precedida por breve discussão acerca da atividade concluída na aula anterior, com duração aproximada de 10 a 15 minutos. Na sequência, havia uma sucinta introdução à atividade que se seguiria, com cerca de 5 a 10 minutos. Então, os estudantes, organizados em grupos, passavam a acompanhar o roteiro e a manipular o material, discutindo entre si e discutindo e apresentando os resultados obtidos à professora.

A seguir será apresentado, no quadro 1, a título de exemplificação, um trecho do roteiro relativo à $2^{\mathrm{a}}$ Lei de Newton, assunto abordado na sexta atividade do semestre. Importante salientar que o tema das atividades anteriores foi "Movimento - observação, registro, representação e análise", de forma que os estudantes já haviam observado diversos tipos de movimento, fazendo análise de seu comportamento quanto à velocidade e à aceleração. Naquele momento, já havia sido trabalhado também o conceito de força.

O objeto sempre se move na direção da força resultante?

1. Você vai trabalhar como um pesquisador agora. Considere as hipóteses abaixo, elas podem estar certas ou erradas. Teste a validade de cada uma delas e decida se são afirmações corretas ou erradas:

a) Um objeto sempre se move na direção e sentido da força resultante que age sobre ele.

b) Um objeto sempre tem sua mudança de movimento (variação de velocidade, $\Delta v$, ou aceleração, a) na direção e sentido da força resultante que atua sobre ele.

Para testar essas hipóteses, pense em pelo menos dois experimentos que você possa fazer para verificar a validade ou a falsidade de cada uma das hipóteses. Registre seus planos por escrito. Para cada um dos testes programados, anote os possíveis resultados e explique qual conclusão poderia tirar de cada possível resultado. Chame sua professora para apresentar seu planejamento.

1. Faça os testes que você planejou. Registre os resultados e suas conclusões.

2. Você conseguiu mostrar que alguma das duas hipóteses é falsa? Você conseguiu mostrar que alguma das duas hipóteses é verdadeira?

3. Vamos um pouco além: é possível provar que alguma das hipóteses é falsa? É possível provar que uma das duas hipóteses é verdadeira? Pense bem, discuta e registre as conclusões. Apresente suas conclusões à professora.

Quadro 1. Trecho do roteiro relativo à 2a Lei de Newton.

Observando os estudantes realizarem essa atividade, foi surpreendente como quase todos, em um primeiro momento, responderam prontamente que a força resultante está sempre na direção e sentido da velocidade. Apesar de, recentemente, em atividades anteriores, terem observado e analisado várias situações (como um objeto 
que sobe ao ser lançado para cima) nas quais força resultante e velocidade estão em sentidos opostos, além de terem estudado a 2 a lei de Newton no Ensino Médio. Mas, ao discutirem entre si e sendo instigados a buscar novas situações para comprovar ou refutar a teoria que estavam desenvolvendo, acabaram por concluir, numa epifania, que, na verdade, a força resultante está sempre na mesma direção e sentido da aceleração. E, embora tenham voltado a ter pensamentos Aristotélicos diversas vezes em aulas posteriores, facilmente retornaram ao ponto de vista Newtoniano ao lembrarem das discussões desta aula.

Nos itens 3 e 4 do trecho do roteiro transcrito, há a proposta de análise sobre o processo de elaboração da teoria e sobre sua validade e extensão. Essa discussão crítica sobre a Ciência faz muito mais sentido para os

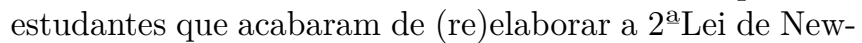
ton. Se tal Lei tivesse sido apenas enunciada e aplicada a casos específicos, a discussão teria ficado muito mais vaga e descontextualizada.

\section{Resultados}

\subsection{FCI}

O teste FCI foi aplicado em todas as turmas no primeiro e no último dias de aula. O ganho percentual normalizado de cada turma foi:

T1a: $4 \%$

T1b: $12 \%$

T2a: $29 \%$

T2b: $24 \%$

Esses resultados sugerem um baixíssimo ganho dos alunos de $1^{\circ}$ período e ganhos razoáveis para as turmas de $2^{\circ}$ período. Outro professor, da mesma instituição, aplicou o teste à sua turma de $2^{\circ}$ período, obtendo um ganho de $24 \%$. A turma tinha 20 alunos e as aulas foram expositivas.

Os resultados das turmas de $2^{\circ}$ período, com ganhos de $24 \%$ e $29 \%$, estão acima do ganho médio obtido com métodos tradicionais, que é de $22 \%$, de acordo com o trabalho de Korff e colaboradores [2]. Trata-se de um resultado muito bom, ainda que bem abaixo dos $39 \%$ de ganho médio obtido através de métodos de aprendizagem ativa. Importante ressaltar que se trata apenas do segundo semestre em que tal método é utilizado por esta professora, de forma que ainda há muito o que se aprimorar, submetendo-o a novos testes e reformulações.

O baixo ganho das turmas de $1^{\circ}$ período será melhor estudado no futuro. Uma hipótese para este resultado é o perfil atípico dos estudantes especificamente neste semestre. Os estudantes apresentavam um nível de conhecimento prévio muito menor do que em turmas típicas e a disciplina não foi planejada para esse perfil diferenciado. Fato que pode ser observado comparando-se os resultados de notas finais e de aprovações destas turmas com as turmas dos mesmos cursos do semestre anterior, apresentados na tabela 1 .

Vê-se que os índices de aprovação foram bem menores no semestre analisado neste trabalho, 2016/2, do que no semestre anterior, bem como as médias das notas finais. É frequente que a turma que ingressa na Universidade no segundo semestre tenha menos conhecimentos prévios que as turmas que ingressam no primeiro semestre mas essa discrepância parece ter sido especialmente acentuada no ano de 2016. Com isso quer-se dizer que a disciplina foi pensada e organizada para um perfil típico de aluno diferente daquele do segundo semestre de 2016. Nas próximas ofertas da disciplina esse perfil dos estudantes deverá ser cuidadosamente estudado e a proposta da disciplina deverá ser adaptada de forma a promover um índice mais alto de aproveitamento. O FCI continuará a ser uma ferramenta adequada para avaliar o ganho dos estudantes.

\subsection{Atitudes dos estudantes}

Vários trabalhos analisando a implementação de métodos de aprendizagem ativa avaliaram as atitudes dos estudantes a respeito da metodologia aplicada, muitos deles apresentando grande aprovação $[12,25,26]$.

Um questionário para avaliar a opinião dos estudantes a respeito da disciplina foi aplicado ao fim do semestre, respondido anonimamente. O número de questionários respondidos foi 15 em T1a, 4 em T1b, 11 em T2a e 5 em T2b. Serão apresentadas a seguir duas das questões propostas, as respostas dadas pelos estudantes estão nas tabelas 2 e 3.

- Nas aulas dessa disciplina você fez atividades práticas através das quais deveria desenvolver os conceitos e as ferramentas da Física. Como você acha que essas aulas contribuíram ou atrapalharam para a construção e o desenvolvimento do seu conhecimento de Física?

- Você recomendaria para um amigo cursar esta disciplina com essa professora, nesse esquema de aula?

A aprovação da disciplina é observada em expressiva maioria: $77 \%$ nas duas questões aprovam sem restrições. E apenas uma pequena minoria $(11,5 \%)$ aprovou com ressalva, mesmo índice dos que desaprovaram a metodologia, de acordo com as duas questões propostas.

Tabela 1: Aprovação e média final das turmas de 1o período em cada um dos semestres letivos de 2016.

\begin{tabular}{lcccc}
\hline & \multicolumn{2}{c}{$2016 / 1$} & \multicolumn{2}{c}{$2016 / 2$} \\
\hline & T1a & T1b & T1a & T1b \\
\hline Aprovação & $50 \%$ & $58 \%$ & $27 \%$ & $33 \%$ \\
\hline Média final (em 100) & 59 & 53 & 40,5 & 37 \\
\hline
\end{tabular}


Tabela 2: Opiniões dos estudantes sobre a contribuição das atividades práticas para a construção de seus conhecimentos.

\begin{tabular}{|c|c|c|c|c|c|c|}
\hline & Contribuíram & $\begin{array}{l}\text { Contribuíram comentá- } \\
\text { rio }\end{array}$ & Atrapalharam & $\begin{array}{l}\text { Atrapalharam comen- } \\
\text { tário }\end{array}$ & Neutro & Neutro comentário \\
\hline T1a & 15 & $\begin{array}{l}\text { "Acho muito mais dida- } \\
\text { tico observar e ver na re- } \\
\text { alidade as coisas aconte- } \\
\text { cendo." } \\
\text { "Essa aula contribui } \\
\text { muito na aprendizagem, } \\
\text { pois sai da teoria e de } \\
\text { conceitos abstratos, mos- } \\
\text { trando a real aplicação } \\
\text { dos conceitos." }\end{array}$ & 0 & & 0 & \\
\hline T1b & 1 & & 2 & $\begin{array}{l}\text { "Não entendia muito } \\
\text { bem as atividades fei- } \\
\text { tas em grupo" }\end{array}$ & 1 & $\begin{array}{l}\text { "Acho, que em parte } \\
\text { pode ter ajudado por ver } \\
\text { o que acontece de ver- } \\
\text { dade mas a atividade em } \\
\text { si achei que contribuiu } \\
\text { pouco, pois acho melhor } \\
\text { a apresentação da matéria } \\
\text { com atividades em folha } \\
\text { para melhorar nosso co- } \\
\text { nhecimento" }\end{array}$ \\
\hline T2a & 6 & $\begin{array}{l}\text { "Ajudaram a entender } \\
\text { melhor como as coisas re- } \\
\text { almente acontecem, mais } \\
\text { do que isso, até ficou } \\
\text { mais fácil de entender os } \\
\text { conceitos, equações, etc. } \\
\text { Enfim, "tornou a física } \\
\text { um pouco mais física"." } \\
\text { "As aulas práticas ajudam } \\
\text { a perceber melhor o que } \\
\text { acontece e isso faz com } \\
\text { que eu possa compreen- } \\
\text { der melhor a teoria" }\end{array}$ & 2 & $\begin{array}{l}\text { "Acredito que algu- } \\
\text { mas questões não ti- } \\
\text { nham a necessidade } \\
\text { de serem feitas e a } \\
\text { atividade poderia ser } \\
\text { mais rápida" } \\
\text { "Atrapalham muito o } \\
\text { aprendizado. Por mais } \\
\text { q seja interessante as } \\
\text { práticas tóricas elas se } \\
\text { tornam impossíveis de } \\
\text { fazer sem o conheci- } \\
\text { mento da matéria, que } \\
\text { só é dada um sucinta } \\
\text { revisão" }\end{array}$ & 3 & $\begin{array}{l}\text { "Na minha opinião, o for- } \\
\text { mato de atividades para o } \\
\text { entendimento da matéria } \\
\text { é muito útil para a } \\
\text { formaçao. Porém, acho } \\
\text { que deveríamos ter uma } \\
\text { pequena mescla de uma } \\
\text { aula teórica antes de } \\
\text { entrarmos na atividade } \\
\text { prática." } \\
\text { "Foram muito boas pois } \\
\text { assim consegui visualizar } \\
\text { melhor oq era explicado, } \\
\text { porém, essas atividades } \\
\text { nos deixaram mais disper- } \\
\text { sos" }\end{array}$ \\
\hline $\mathrm{T} 2 \mathrm{~b}$ & 5 & $\begin{array}{l}\text { "Na maior parte concei- } \\
\text { tos mais distantes do dia- } \\
\text { a-dia eu achei que as } \\
\text { atividades praticas con- } \\
\text { tribuíram, e muito para } \\
\text { a compreensão delas." }\end{array}$ & 0 & & 0 & \\
\hline Total & $27(77 \%)$ & & $4(11,5 \%)$ & & $4(11,5 \%)$ & \\
\hline
\end{tabular}

Tabela 3: Respostas dos estudantes ao questionamento se eles indicariam a disciplina para um amigo.

\begin{tabular}{|c|c|c|c|c|c|c|}
\hline & Recomendaria & $\begin{array}{l}\text { Recomendaria } \\
\text { comentário }\end{array}$ & $\begin{array}{l}\text { Não recomenda- } \\
\text { ria }\end{array}$ & $\begin{array}{l}\text { Não recomendaria co- } \\
\text { mentário }\end{array}$ & $\begin{array}{l}\text { Recomendaria com } \\
\text { ressalva ou talvez }\end{array}$ & Talvez comentário \\
\hline T1a & 14 & & 0 & & 1 & $\begin{array}{l}\text { "Sim, ressalvado que um } \\
\text { pouco mais lento tenho } \\
\text { nada a reclamar." }\end{array}$ \\
\hline T1b & 1 & & 2 & $\begin{array}{l}\text { "Recomendaria estu- } \\
\text { dar com a professora, } \\
\text { mas não com esse es- } \\
\text { quema de aula." }\end{array}$ & 1 & $\begin{array}{l}\text { "se eles estudasse muito } \\
\text { sim" }\end{array}$ \\
\hline T2a & 8 & & 2 & $\begin{array}{l}\text { "Para a pessoa que } \\
\text { tem dificuldade em } \\
\text { física não recomendo" }\end{array}$ & 1 & $\begin{array}{l}\text { "Recomendaria com al- } \\
\text { guns avisos, como es- } \\
\text { tudo extra classe mais re- } \\
\text { forçado." }\end{array}$ \\
\hline $\mathrm{T} 2 \mathrm{~b}$ & 4 & & & & 1 & $\begin{array}{l}\text { "Caso tenha mais aulas } \\
\text { expositivas." }\end{array}$ \\
\hline Total & $27(77 \%)$ & & $4(11,5 \%)$ & & $4(11,5 \%)$ & \\
\hline
\end{tabular}




\section{Conclusões}

A despeito do construtivismo ser um forte paradigma educacional no Brasil, as disciplinas de Física dos Ensinos Médio e Superior são trabalhadas, em sua imensa maioria, com práticas tradicionais baseadas em aulas expositivas.

Foi apresentada uma experiência em uma disciplina de Mecânica, no Ensino Superior, inspirada no método ISLE, que propõe que os estudantes aprendam Física de forma semelhante à maneira através da qual os cientistas constroem a Ciência.

A fim de mensurar o ganho dos estudantes com a utilização do método apresentado, um pré-teste e um pós-teste foram aplicados. Verificou-se que para as duas turmas de $1^{\circ}$ período o resultado foi muito ruim. Por outro lado, nas duas turmas de $2^{\circ}$ período o resultado foi satisfatório, atingindo percentual maior que a média dos índices obtidos por métodos tradicionais, de acordo com o estudo de Korff [2]. As turmas têm um pequeno número de estudantes, o que enfraquece o resultado, do ponto de vista estatístico, mas não o invalida.

Questionários de satisfação foram preenchidos pelos estudantes anonimamente após o fim do semestre, alcançando os seguintes percentuais: $77 \%$ dos alunos que responderam avaliaram que as atividades práticas contribuíram para sua aprendizagem e $77 \%$ recomendariam, sem restrição, o estudo da disciplina neste formato a um amigo. Por outro lado, 11,5\% avaliaram que as aulas práticas atrapalharam o aprendizado e outros $11,5 \%$ consideraram que tanto atrapalharam quanto contribuíram. Ainda 11,5\% recomendariam com restrições e $11,5 \%$ não recomendariam a disciplina.

Conclui-se, com isso, que, em média, o ganho de aprendizagem obtido foi semelhante ao de cursos convencionais, com a vantagem da mudança atitudinal que, presumivelmente, terá impacto em futuras disciplinas cursadas pelos estudantes.

\section{Referências}

[1] T.C. Rego, Vygotsky: Uma Perspectiva HistóricoCultural da Educação (Editora Vozes, Petrópolis, 1994).

[2] J.V. Korff, B. Archibeque, K.A. Gomez, T. Heckendorf, S.B. McKagan, E.C. Sayre, E.W. Schenk, C. Shepherd and L. Sorell, American Journal of Physics 84, 969 (2016).

[3] J. Piaget, in: Manual de Psicologia da Criança, editado por L. Carmichael (EDUSP, São Paulo, 1975), v. 4, p. 89

[4] L.S. Vigotski, Pensamento e Linguagem (Martins Fontes, São Paulo, 2008).

[5] L.C. McDermott and P.S. Shaffer, Tutorials in Introductory Physics (Prentice Hall, Upper Saddle River, 2002).

[6] L. McDermott, American Journal of Physics 59, 301 (1991).

[7] E. Mazur, Peer Instrucrion: A User's Manual (Pearson Education, Upper Saddle River, 1997).

[8] V. Oliveira, E.A. Veit e I.S. Araujo, Caderno Brasileiro de Ensino de Física 32, 180 (2015).
[9] A.V.R. Araujo, E.S. Silva, V.L.B. Jesus e A.L. Oliveira, Revista Brasileira de Ensino de Física 39, e2401 (2017).

[10] A.F. Faria e A.M. Vaz, in: Anais do X Encontro Nacional de Pesquisa em Educação em Ciências, Águas de Lindóia, 2015 , p. 1.

[11] A.V. Morais e J.L. Matheus-Valle, in: Anais do XVIII Simpósio Nacional de Ensino de Física, Vitória, 2009, p. 1.

[12] M.G. Müller, I.S. Araujo, E.A. Veit e J. Schell, Revista Brasileira de Ensino de Física 39, e3403 (2017).

[13] I.S. Araujo e E. Mazur, Caderno Brasileiro de Ensino de Física 30, 362 (2013).

[14] E. Etkina, American Journal of Physics 83, 669 (2015)

[15] D. Hestenes, M. Wells and G. Swackhamer, The Physics Teacher 30, 141 (1992).

[16] V.B. Henriques; C.P.C. Prado and A.P. Vieira. Rev. Bras. Ensino Fís. 36, 1 (2014).

[17] T.E. Oliveira, I.S. Araujo e E.A. Veit, Caderno Brasileiro de Ensino de Física 33, 962 (2016).

[18] R.J. Santos e D.G.G. Sazaki, Revista Brasileira de Ensino de Física 37, 3506 (2015).

[19] E. Etkina, Scientific Abilities, disponível em http://www islephysics.net/, acesso em 03/06/2017.

[20] E. Etikna and V. Heuvelen in: Reviews in PER Vol. 1: Research-Based Reform of University Physics, edited by E.F. Redish and P.J. Cooney (American Association of Physics Teachers, College Park, 2007), available in http://www. compadre.org/PER/per_reviews/ media/volume1/ISLE-2007.pdf, acessed in 03/06/2017.

[21] J.E. Parreira, Roteiros das Aulas Disponibilizados aos Estudantes, disponível em http://www.icei pucminas.br/professores/juliaparreira/, acesso em 03/06/2017.

[22] D. Halliday, R. Resnick e J. Walker, Fundamentos de Física 1 - Mecânica (LTC, São Paulo, 2016).

[23] F. Sears e M. Zemansky, Física 1 - Mecânica (Pearson, São Paulo, 2008).

[24] P.A. Tipler e G. Mosca, Física para Cientistas e Engenheiros: Mecânica, Oscilaçôes e Ondas, Termodinâmica, volume 1 (LTC, São Paulo, 2009).

[25] A.L. Rudolph, B. Lamine, M. Joyce, H. Vignolles and D. Consiglio, Physical Review Special Topics - Physics Education Research 10, 010103 (2014).

[26] C.H. Crouch and E. Mazur, American Journal of Physics 69, $970(2001)$ 